\title{
A Proactive Approach to Evaluating Intersection Safety Using Hard-Braking Data
}

\author{
Margaret Hunter $^{1}$ (D) Enrique Saldivar-Carranza ${ }^{1}$ (D) Jairaj Desai ${ }^{1}$ (D) Jijo K. Mathew ${ }^{1}$ (D) Howell Li $^{1}$ (D) \\ Darcy M. Bullock ${ }^{1}$ (D)
}

Received: 25 November 2020 / Revised: 19 March 2021 / Accepted: 24 March 2021 / Published online: 3 April 2021

(c) The Author(s) 2021

\begin{abstract}
Typical safety improvements at signalized intersections are identified and prioritized using crash data over 3-5 years. Enhanced probe data that provides date, time, heading, and location of hard-braking events has recently become available to agencies. In a typical month, over six million hard-braking events are logged in the state of Indiana. This study compared rear-end crash data over a period of 4.5 years at 8 signalized intersections with weekday hard-braking data from July 2019. Using Spearman's rank-order correlation, results indicated a strong correlation between hard-braking events and rear-end crashes occurring more than $400 \mathrm{ft}$ upstream of an intersection. The paper concludes that using a month or two of hardbraking events occurring upstream from the stop bar may be a useful tool to screen potential locations with elevated rear-end crashes. Using these techniques described in this paper, new commercially available hard-braking data sources will provide an opportunity for agencies to follow up with mitigation measures addressing emerging problems much quicker than typical practices that rely on $3-5$ years of crash data.
\end{abstract}

Keywords Safety $\cdot$ Vehicle probe data $\cdot$ Big data $\cdot$ Hard-braking $\cdot$ Crashes

\section{Introduction}

Advancements in traffic signal event logging in the past decade (Day et al. 2014; Sturdevant et al. 2012) have produced performance metrics that assess red-light running (Chen et al. 2017; Lavrenz et al. 2016), progression quality (Day et al. 2011; Hainen et al. 2014; Zheng et al. 2014), and queues (Wu et al. 2010). However, agencies still screen

Jijo K. Mathew

kjijo@purdue.edu

Margaret Hunter

hunter87@purdue.edu

Enrique Saldivar-Carranza

esaldiva@purdue.edu

Jairaj Desai

desaij@purdue.edu

Howell Li

howell-li@purdue.edu

Darcy M. Bullock

darcy@purdue.edu

1 Joint Transportation Research Program, Purdue University, West Lafayette, IN, USA signalized intersections and approaches for safety improvements by utilizing crash data from the previous 3-5 years (Federal Highway Administration 2011; Indiana Department of Transportation 2012). Due to the relative infrequency of crashes at many locations, this multi-year analysis of data is needed to ensure the validity and accuracy of the agency's statistical models. However, this method is considered reactive as agencies must wait for a substantial crash history to develop as evidence for proceeding with safety improvement projects. There is a growing interest in the industry to replace the historical method with surrogate events to reduce the time between data collection and the implementation of safety improvements.

Since the 1960s, there has been interest in supplementing or replacing crash counts with traffic conflicts (Perkins and Harris 1968). Conflicts occur more frequently than crashes and are caused by the same failures that result in crashes (Tarko 2020). The higher number of conflicts combined with their similar causations to crashes make them attractive to agencies trying to statistically determine areas for safety improvements. However, conflicts have a disadvantage; they can be difficult to collect, require trained personnel, and can be dependent on the subjective ratings of the observer. 
Crowdsourced probe data that provide average segment speeds (Remias et al. 2013) have been commercially available for some time. Recent developments of probe data now include data elements such as hard-braking and acceleration from onboard sensors (Wejo and CtrlShift 2020). These data, aggregated by third-party vendors, can provide agencies with hard-braking events on their roadways.

\section{Motivation}

In July 2019, there were over 6 million hard-braking events in Indiana. In contrast, during the same month, there were only 17,652 crashes in Indiana, which represents $0.3 \%$ of the total number of hard-braking events. The motivation of this study is to use emerging crowdsourced hard-braking events for agency-wide screening of intersections and approaches for potential safety improvements, and followup with mitigation measures addressing emerging problems much quicker than typical practices that rely on 3-5 years of crash data.

\section{Literature Review}

In the early years of traffic conflict analysis, a traffic conflict was defined as the occurrence of an evasive maneuver, braking, or a lane change (Older and Spicer 1976). Although there are many studies that analyze traffic conflicts, very few have looked at hard-braking events at a large scale. Bagdadi and Varhelyi presented the critical jerk method to differentiate between critical and potentially critical events (Bagdadi and Várhelyi 2013). In a following paper, Bagdadi compared the critical jerk method to the longitudinal acceleration method in a naturalistic driving study focused on safety critical braking events. The study concluded that the critical jerk method was about 1.6 times better than the longitudinal acceleration method at identifying near-crashes (Bagdadi 2013). Stipancic et al. compared hard-braking events and hard-accelerating events to crash frequency for links and intersections. For both hard-braking events and hard-acceleration events, a positive correlation was found between the number of events and crash frequency for both links and intersections; however, the correlation was stronger for intersections (Stipancic et al. 2018). Li et al. analyzed roughly 1.5 million crowdsourced hard-braking events at signalized intersections, work zones, interchanges, and entry/exit ramps. The study concluded that dilemma zones could be identified by hard-braking events along with work zones that are in need of geometry changes or more advanced warning signs (Li et al. 2020).

Using video camera footage, Essa and Sayed concluded that the highest frequency of traffic conflicts occurred at the beginning of green as the queue is discharged at a low speed while vehicles joining the queue approach at a high speed; nevertheless, they considered most of these conflicts to be low severity (Essa and Sayed 2019). While Mekker et al.'s study focused on free flow and congested conditions on interstates, the study determined that a crash was approximately 24 times more likely to occur in congested conditions than in free flowing conditions (Mekker et al. 2014). One common cause of congestion on interstates is construction activity. Desai et al. found that, in and around interstate work zones, there was approximately $1 \mathrm{crash} /$ mile for every 147 hard-braking events (Desai et al. 2020).

In a study using floating car data, Kveladze and Agerholm developed a GeoVisual Analytics approach to evaluate arterial safety with a focus on vulnerable road users. This study focused on segments far from intersections and other traffic controlling measures and was able to identify times and locations where pedestrians illegally crossed the arterial roads (Kveladze and Agerholm 2020).

One concern of crowdsourced data is the penetration levels required to accurately represent the traffic flow of the network. Day et al. determined in sequential studies that aggregate data at penetration levels ranging from 0.09 to $0.8 \%$ provide an acceptable representation of the corridor for actionable corridor retiming recommendations (Day et al. 2017; Day and Bullock 2016).

\section{Proposed Approach}

This paper presents a technique that analyzes hard-braking events relative to the stop bar of a signalized intersection. These events are aggregated by weekdays over the period of 1 month. The statistical relation between hard-braking locations relative to the stop bar and historical crash rates is then examined to determine if hard-braking data can provide a scalable approach to screen for potential safety improvement projects.

\section{Study Corridor}

This study utilizes weekday hard-braking data collected between July 1 and July 31, 2019 at eight intersections along a corridor on SR-37, south of Indianapolis, IN (Fig. 1b, callout ii). The corridor is a 4- to 6-lane principal arterial with a speed limit of $55 \mathrm{mph}$. The volume along the corridor varies between 64,000 vehicles/day at the northernmost intersection, 49,000 vehicles/day in the middle of the corridor, and 38,000 vehicles/day at the southernmost intersection. Indianapolis commuters living south of the city use this corridor to commute northbound in the morning and southbound in the evening. The studied intersections (Fig. 1c), in north to south 
Fig. 1 Indiana signalized corridor location for hard-braking event study

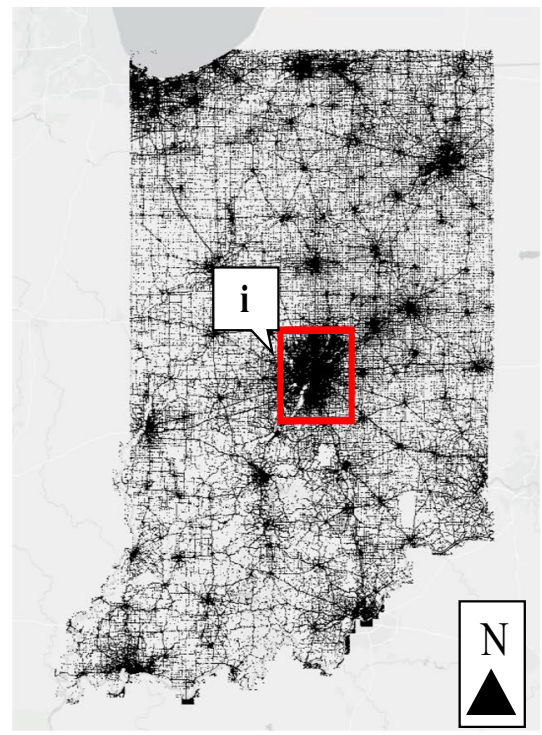

(a) 6,172,453 hard-braking events during July 2019 in IN

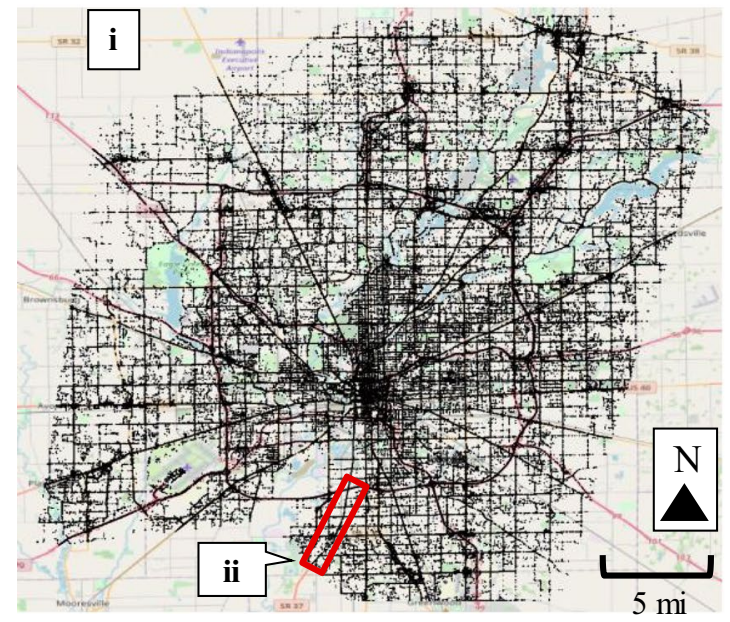

(b) 1,687,533 hard-braking events during July 2019 in the greater Indianapolis area

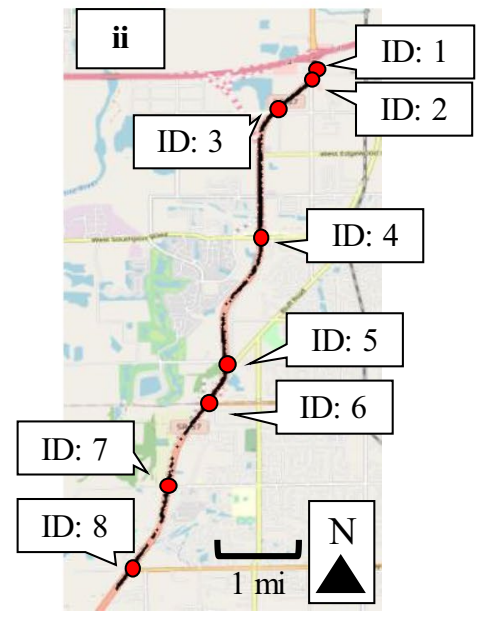

(c) 15,863 hard-braking events during July 2019 between ID: 1 and ID:8

SR-37. Study corridor shown with intersection labels order, are Thompson Rd., Harding St., Epler Ave., Southport Rd., Wicker Rd., County Line Rd., Fairview Rd. and Smith Valley Rd. These intersections run on an actuated-coordinated operation, most of them with a cycle length of $120 \mathrm{~s}$, across four different weekday time-of-day (TOD) plans:

AM peak (AM): 05:00-09:15

Mid-day (MD): 09:15-14:30

PM peak (PM): 14:30-19:00

Evening (EV): 19:00-22:00

In addition to showing the location for SR-37 in Indiana, Fig. 1 shows the locations of the over 6 million July 2019 hard-braking events in Indiana (Fig. 1a). Of the 6 million hard-braking events, almost 16,000 occurred along the roughly 6.5 mile corridor (Fig. 1c).

\section{Hard-Braking Events}

\section{Data}

The hard-braking event data used in this study were made commercially available by data providers that worked directly with original equipment manufacturers (OEMs). The enhanced probe data from these connected passenger vehicles included an anonymized unique identifier with 
timestamp, geolocation, speed, heading and hard-braking/ acceleration as attributes. The provider of this data defined hard-braking events as any vehicle decelerations with a magnitude greater than $8.76 \mathrm{ft} / \mathrm{s}^{2}(0.272 \mathrm{~g})$.

In July 2019, there were over 1.5 million events in Greater Indianapolis (Fig. 1b), almost 16,000 events along the study corridor (Fig. 1c), and about 10,000 events at the corridor's eight intersections. Every weekday, those intersections experienced an average of 321 events, and every hour, they experienced an average of 14 events. The penetration level of this data is estimated to be around $2 \%$.

\section{Methodology}

The hard-braking events analyzed in this paper were sorted by intersection, distance from stop bar, and speed at which the vehicle was traveling when the hard-braking event occurred. In this study, the analysis was limited to through movements. A geofence region was drawn along the through lanes for each approach. This upstream region began parallel to the opposing direction's stop bar and ended $1320 \mathrm{ft}$, a quarter mile, upstream. Once the geofenced region was defined, the hard-braking events that occurred within those regions were selected, and the GPS locations of each hardbraking event were compared to the location of the stop bar to calculate the distance from stop bar. Figure 2 a shows the hard-braking events for an area along the study corridor. Figure $2 b$ shows the upstream geofence regions and the geofenced hard-braking events color coded by speed. The $400 \mathrm{ft}$ boundary, relative to the stop bar, roughly corresponds to the location of the dilemma zone detectors at this intersection (Gazis et al. 1960; Parsonson 1978; Zegeer and Deen 1978).

\section{Analysis: Hard-Braking Events by Approach}

The hard-braking events are classified by their distance from the stop bar to study the impact of dilemma zone (Gazis et al. 1960; Parsonson 1978; Zegeer and Deen 1978) and queuing. Type II dilemma zone has been defined in previous literature as the road segment where there is a $10-90 \%$ probability of a vehicle stopping at the beginning of the yellow light (Parsonson 1978). The occurrence of hard-braking events less than $400 \mathrm{ft}$ (location of advance detector upstream of stop bar at $55 \mathrm{MPH}$ speed limit zone) at lower speeds are possibly due to vehicles stopping for the red light, whereas such occurrences at higher speeds could be due to dilemma zone issues. Hard-braking events occurring at distances greater than 400 $\mathrm{ft}$ from the stop bar are potentially due to long queues during oversaturated conditions.

Figure 3 shows the number of weekday hard-braking events occurring at each intersection, stacked by distance from the stop bar, aggregated over the month of July 2019. For both NB and SB approaches, the majority of the hardbraking events occur within $400 \mathrm{ft}$ of the stop bar. However, there are a few intersections (\#8 Smith Valley Rd., in NB and \#4, Southport Rd., and \#5, Wicker Rd. in SB) where more than $40 \%$ of hard-braking events occurred more than $400 \mathrm{ft}$ from the stop bar.
Fig. 2 Visualization of hardbraking event processing
- Hard-braking event

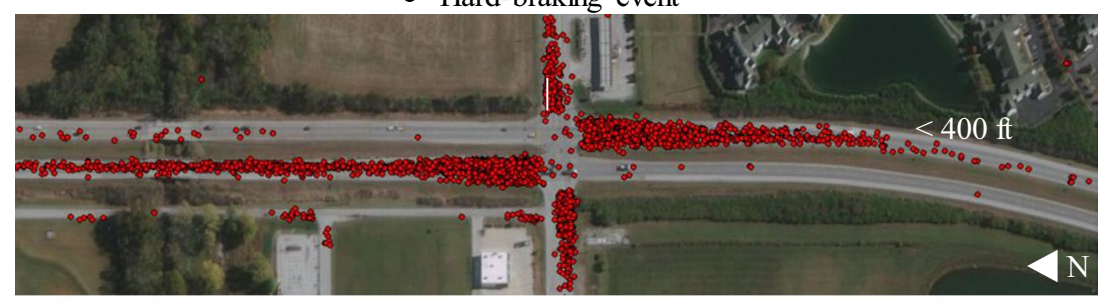

(a) Approximately 3,000 hard-braking event points around the intersection of SR 37 and \#4 Southport Rd

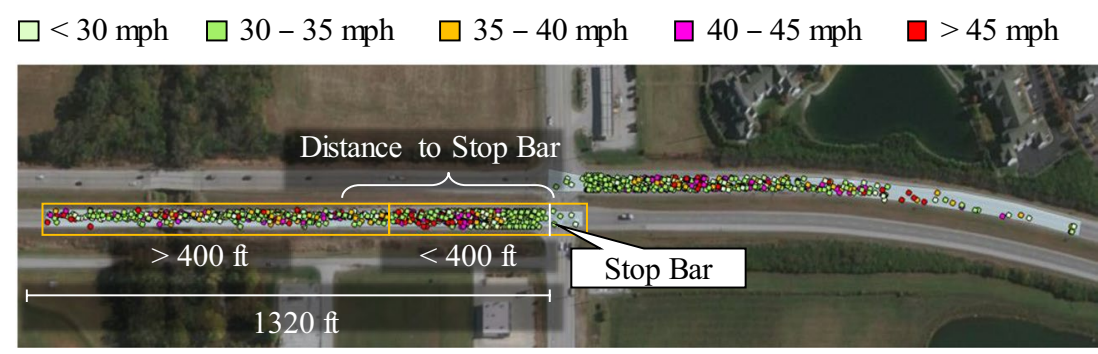

(b) Approximately 1,600 hard-braking points captured by the north and southbound upstream geofence regions. Hard-braking event points are colorized by speed of vehicle at the time of the event 


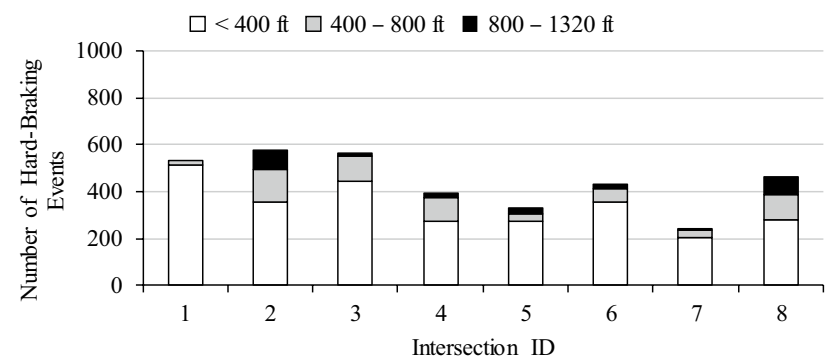

(a) Northbound, SR-37

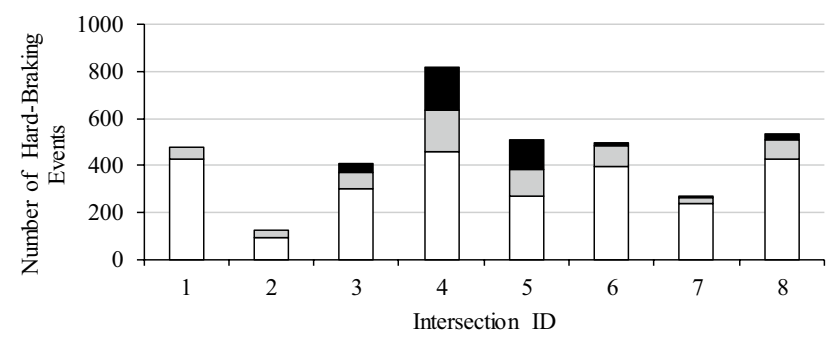

(b) Southbound, SR-37

Fig. 3 Number of weekday hard-braking events by intersection and distance upstream of stop bar

To understand the temporal nature of the hard-braking events and their distances from the stop bar, a heatmap was generated. Figure 4 illustrates a heatmap of the number of hard-braking events, during weekdays in July 2019, on the NB approach over a 24-h period (30-min bins) across two distance categories-less than $400 \mathrm{ft}$ and greater than $400 \mathrm{ft}$. For the less than $400 \mathrm{ft}$ category, the majority of hard-braking events occur during the AM, MD and PM plans (Fig. 4a), with no clear pattern or trend. For the 400-1320 $\mathrm{ft}$ range (Fig. 4b), there are generally fewer hard-braking events, except for perhaps intersection 8 during the PM plan.

Figure 5 shows a heatmap similar to Fig. 4 , for the SB approach. Hard-braking events within $400 \mathrm{ft}$ of the intersection (Fig. 5a) are generally higher for the PM plan, especially at intersection 8, Smith Valley Rd. Figure 5b, which comprises of events occurring beyond $400 \mathrm{ft}$, shows a different pattern than the northbound approaches. Intersection 4, Southport Rd., and intersection 5, Wicker Rd., experience a large number of hard-braking events during the PM plan. This could be indicative of hard-braking events that occur at the back of long queues during the PM peak period.

\section{Analysis: Hard-Braking Patterns by Intersection}

To further investigate the pattern of hard-braking events, a histogram of the events stacked by speeds are plotted for different time of day plans over their distance from the stop bar. Figures 6 and 7 present the two such patterns, in regard to intersections along the SR-37 corridor, for weekdays between 5:00 AM and 10:00 PM in July 2019.

Figure 6 shows the hard-braking events at the southbound approach of intersection 4, Southport Rd. During the PM time plan (Fig. 6b), hard-braking events are occurring consistently for the entirety of the quarter-mile from the stop bar, with very few of those hard-braking events occurring at speeds over $45 \mathrm{mph}$. The aerial image in Fig. 6a shows that
Fig. 4 Heatmap of weekday hard-braking events by intersection for northbound SR-37, in July 2019

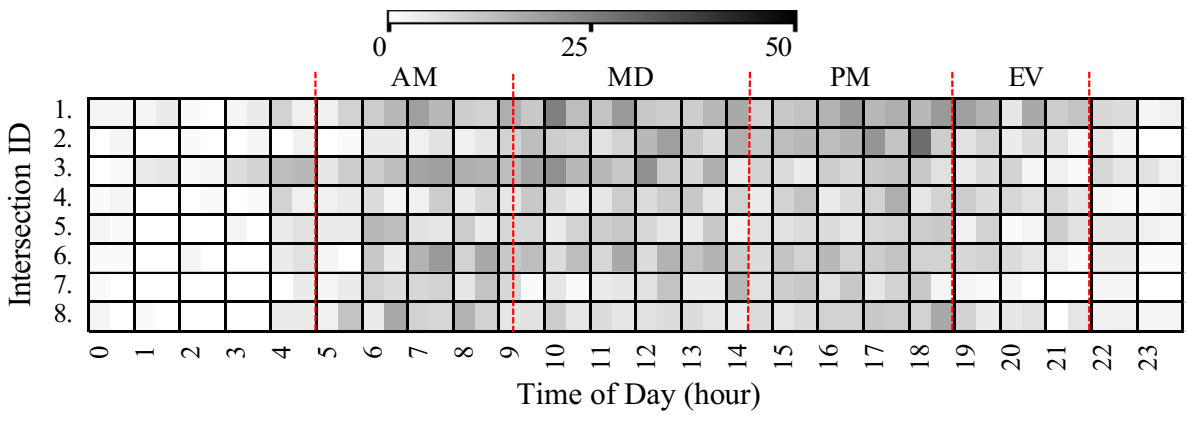

(a) Less than $400 \mathrm{ft}$ from stop bar

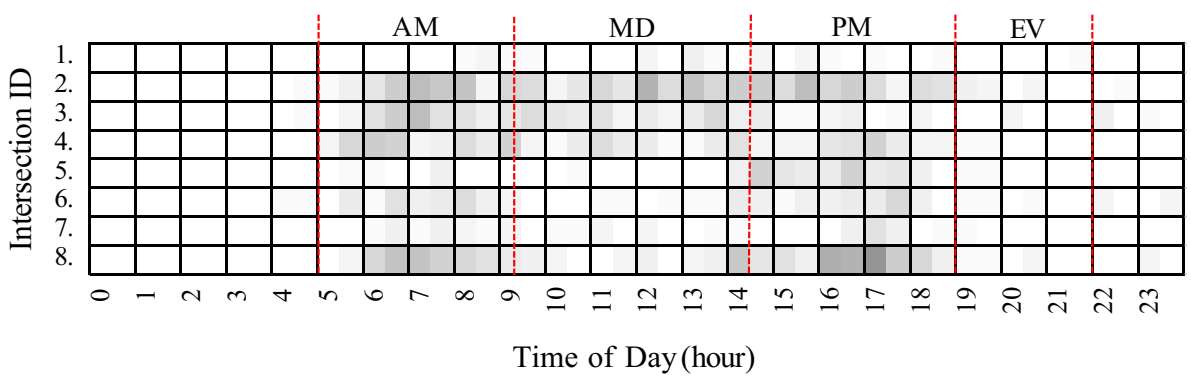

(b) Greater than $400 \mathrm{ft}$ from stop bar 
Fig. 5 Heatmap of weekday hard-braking events by intersection for southbound SR-37, in July 2019

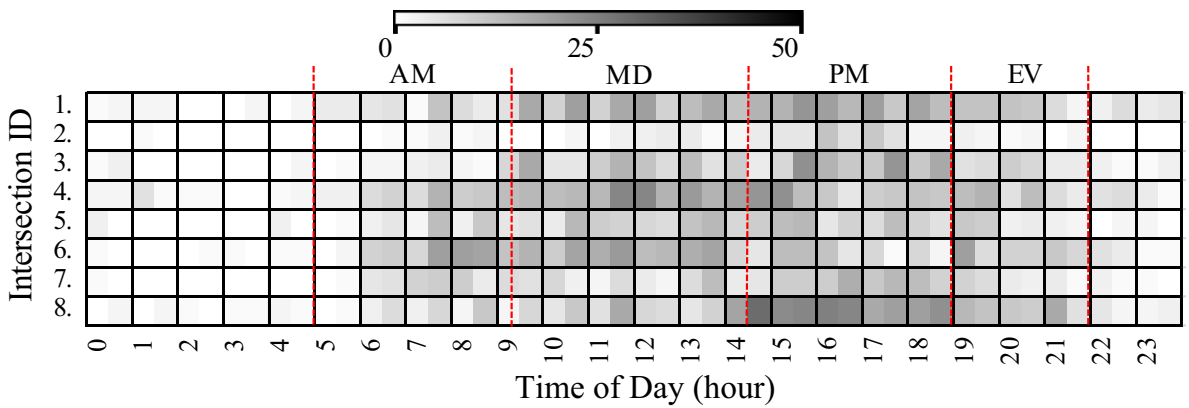

(a) Less than $400 \mathrm{ft}$ from stop bar

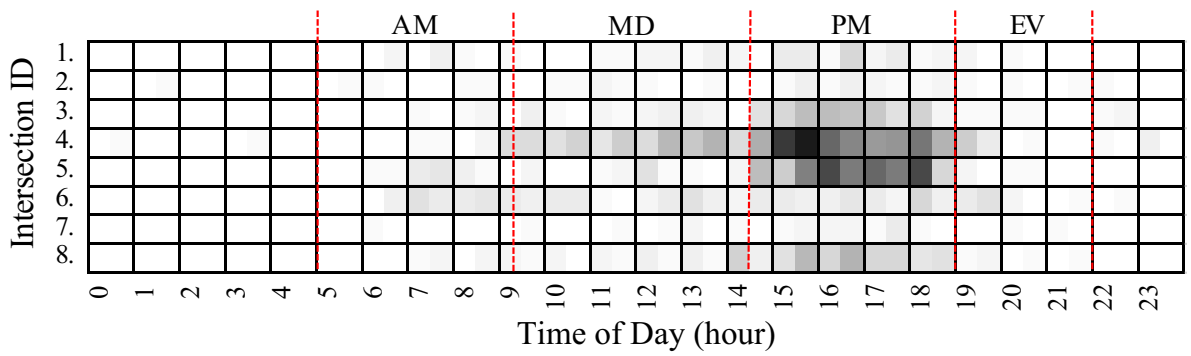

(b) Greater than $400 \mathrm{ft}$ from stop bar

the intersection crash count to 551 crashes, of which 391 were weekday crashes and 261 of those indicated a rear-end collision.

\section{Distribution of Crashes Among Intersections on Study Corridor}

Figure 8 shows a stacked bar graph of the number of crashes categorized by manner of collision that occurred adjacent to the eight intersections along SR-37 on weekdays during the 4.5-year study period. The southbound approach of intersection 4, Southport Rd., stands out as having the most crashes (71 crashes) for the 4.5 -year period. Of those 71 crashes, $70 \%$ were rear-end collisions. Likewise, the second and third highest crash count approaches, southbound intersection 5, Wicker Rd., and northbound intersection 8, Smith Valley Rd., have $75 \%$ and $65 \%$, respectively, of their total crash count as rear-end crashes. Overall, $65 \%$ of the 391 recorded weekday crashes on this corridor were rear-end collisions.

\section{Methodology}

Similar to the hard-braking events, crashes are filtered by their different attributes. The crashes are characterized by their recorded manner of collision, distance from stop bar, and time of day. Finally, a statistical analysis is completed. The Spearman's rank-order correlation, Pearson's correlation, and Kendall's correlation tests are applied to the hard-braking event data and the crash data for each intersection. Additionally, a sensitivity analysis is done, and a preliminary model is presented. Rear-end crashes 
Fig. 6 Southbound approach, SR-37 at Southport Road (Intersection 4)

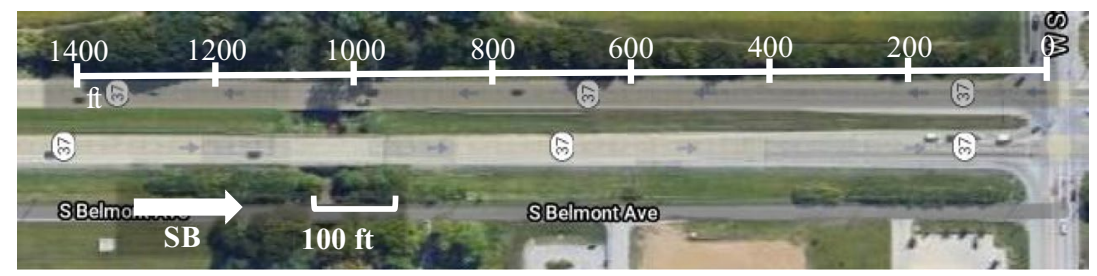

(a) Aerial photo of the southbound approach

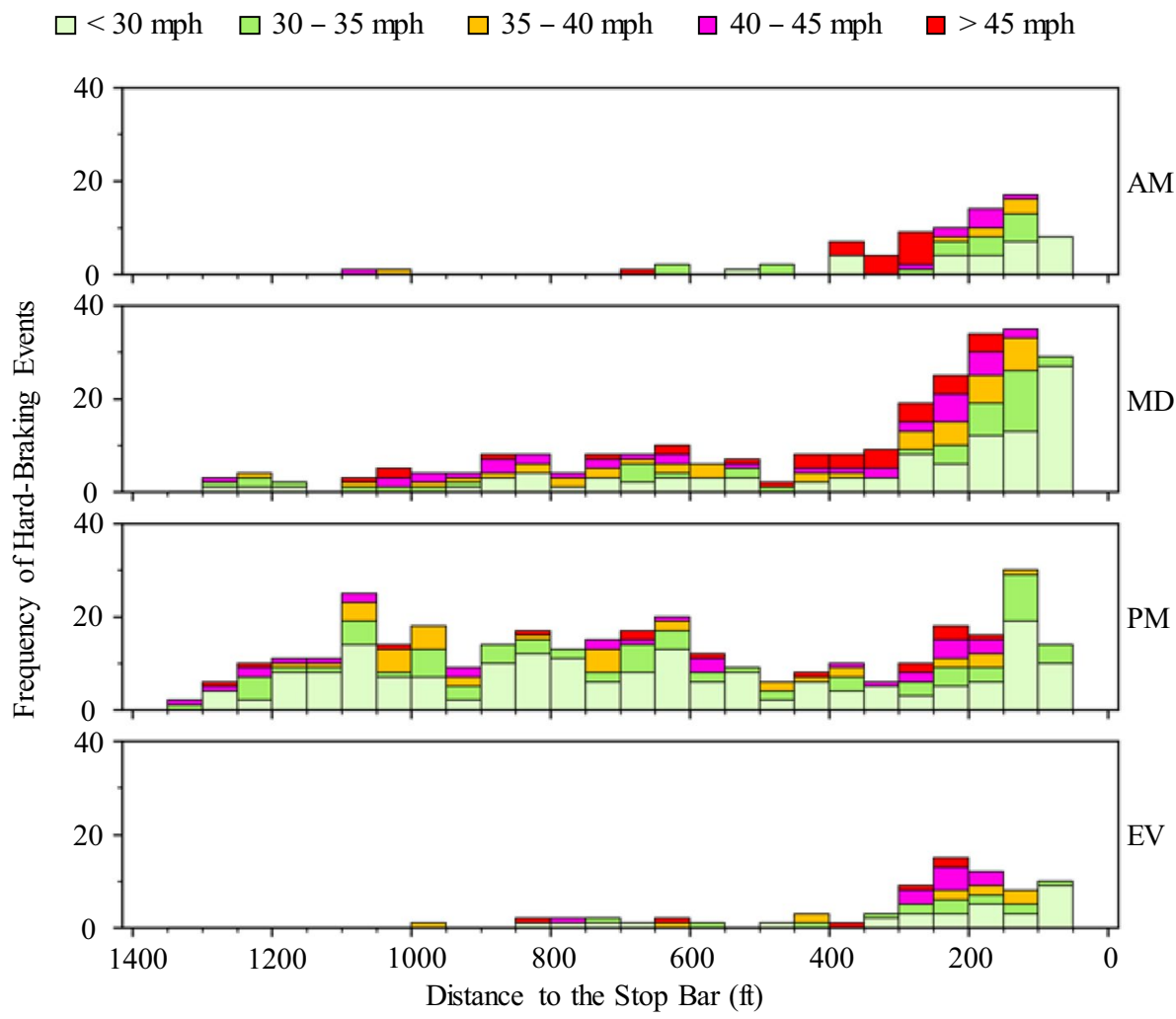

(b) Frequency of hard-braking events by distance to the stop bar and speed for weekdays, July 2019 represented the largest group of crashes among the eight intersections; therefore, the statistical analysis focuses on the comparison between hard-braking events and rear-end crashes.

\section{Analysis: Crashes by Time of Day}

Figure 9 presents a heatmap of weekday crashes aggregated over the study period. Crashes were binned by 30-min periods and assigned to their respective intersections. In the SB approach (Fig. 9b), intersection 4, Southport Rd., and intersection 5, Wicker Rd., stand out in the PM time frame as having a relatively large number of crashes. Visually this is similar to Fig. 5b where Southport Rd. and Wicker Rd. stood out as having a larger number of hard-braking events at a distance of greater than $400 \mathrm{ft}$ from the stop bar.

\section{Correlation Between Hard-Braking Events and Crashes}

\section{Correlation Tests}

In addition to the graphical visualizations highlighting similar patterns between crashes and hard-braking events, a several correlation tests are performed to determine if a linear correlation is present. The aggregated July 2019 weekday hard-braking events occurring over a 30-min period are compared with the aggregated 4.5-year period rear-end crashes occurring over the same 30-min period. First, a simple Spearman rank-order correlation test (Spearman 1904) is conducted to evaluate the monotonic relationship between a pair of data. The correlation coefficient, $r_{s}$, represents the strength of that relationship. There are many interpretations in the literature (Dancey and Reidy 2007; Chan 2003) on 
Fig. 7 Southbound approach, SR-37, at Smith Valley Road (Intersection 8)



(a) Aerial photo of the southbound approach

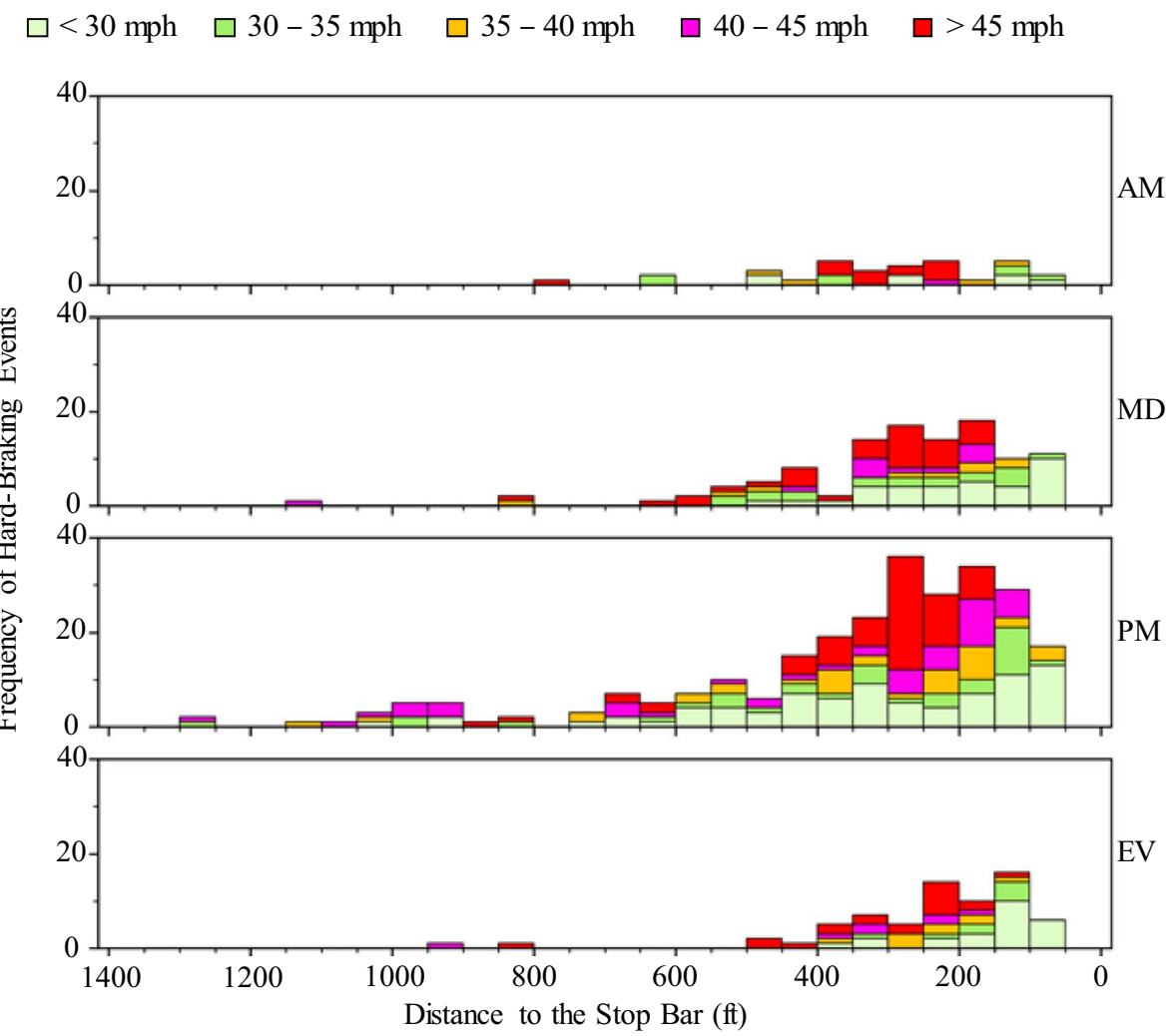

(b) Frequency of hard-braking events by distance from the stop bar and speed for weekdays, July 2019 coefficient thresholds, but this study utilizes a conservative interpretation suggested by Evans (1996) as seen in Table 1.

Tables 2 and 3 show the results of the Spearman test conducted at $95 \%$ and $99 \%$ confidence levels and highlights intersections with a strong correlation, for NB and SB respectively. Results indicate a strong correlation between rear-end crashes and hard-braking events past $400 \mathrm{ft}$ of the stop bar at NB intersection 8, Smith Valley Rd., and SB intersection 4, Southport Rd., and intersection 5, Wicker Rd. A check in the strong correlation box is used if the $r_{s}$ value exceeds the 0.6 threshold shown in Table 1.

Interestingly, while SB intersection 8, Smith Valley Rd. experienced a high number of high-speed hard-braking events within $250 \mathrm{ft}$ of the stop bar (Fig. 7b), this location does not exhibit a strong correlation to rear-end crashes as suggested by prior conflict models (Sharmaet al. 2011).
Along with the Spearman's rank-order correlation test, a Pearson's and a Kendall's correlation test are performed (Pearson 1895; Kendall 1990). Table 4 presents the coefficient interpretations used by this study for the Pearson's and Kendall's correlation tests (Mukaka 2012).

The results for the Pearson's and Kendall's correlation test in SB direction are shown in Tables 5 and 6, respectively. The three intersections that are shown by the Spearman's correlation test to have a strong correlation are also shown to have a moderate correlation by the Pearson's and Kendall's correlation tests. In addition to those three intersections, the Pearson's correlation test also identifies SB intersection 1, Thompson Rd. and SB intersection 4, Southport Rd., as having a moderate correlation between number of hard-braking events and rear-end crashes in the under $400 \mathrm{ft}$ region. 




(a) Northbound, SR-37

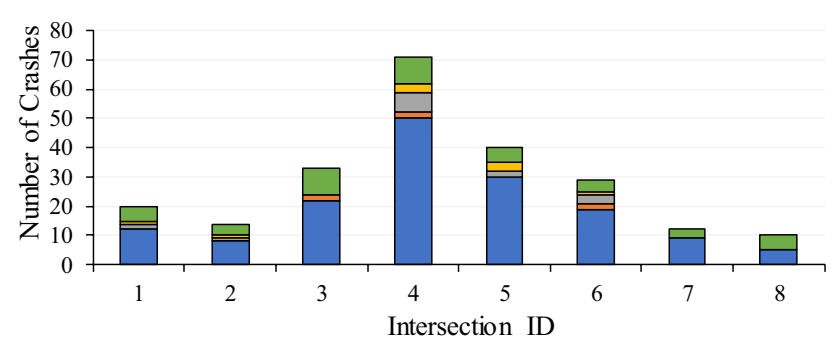

(b) Southbound, SR-37

Fig. 8 Number of weekday crashes by intersection and type on SR-37, between January 1, 2016 and July 9, 2020

\section{Sensitivity Analysis}

To determine if one month of hard-braking event data are sufficient to suggest a reasonable correlation between hardbraking events and crashes, a sensitivity analysis using
Spearman's correlation is performed. While this study primarily uses one month of hard-braking data collected from July 2019, the sensitivity analysis includes data from July and August 2019. Figure 10 shows the results of this analysis. The two plots in Fig. 10 show that the $r_{s}$ values plateau around 4 weeks' worth of data. This suggests that one month of hard-braking data is sufficient to result in a reliable correlation with over 4.5 years' worth of crash data.

\section{Statistical Modelling}

To explore the relationship between number of hard-braking events, volumes, and other intersection attributes and the number of crashes, a statistical model is developed. The response variable in this study, the number of crashes across the eight intersections by 30 -min bins, is discrete, nonnegative integers which are typically modeled by a count data model. Commonly, these count data models are either a Poisson model or a negative binomial regression model (Washington 2010).

The Poisson model, which is often used to model rareevent count data, like crashes, requires the mean and variance of the response variable to be equal. When the variance is greater than the mean, there is over-dispersion in the data, which requires complex models such as the negative binomial model.

The Poisson model assumes the response variable y has a Poisson distribution and that the logarithm of expected
Fig. 9 Heatmap of frequency of weekday crashes between January 1, 2016 and July 9, 2020

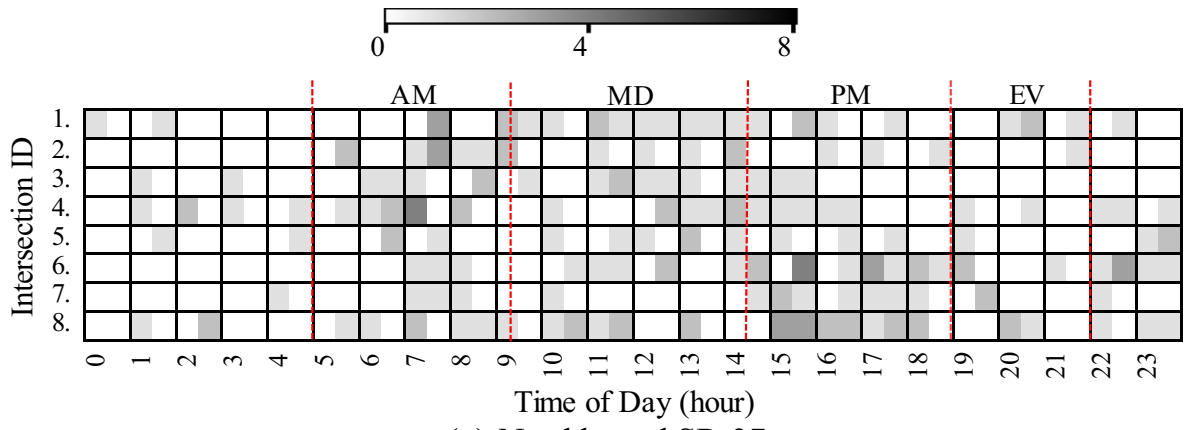

(a) Northbound SR-37

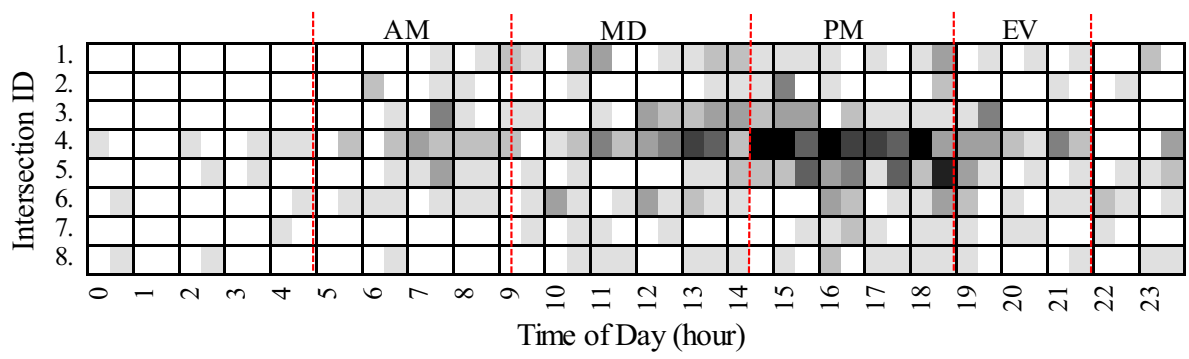

(b) Southbound SR-37 
Table 1 Interpretation of correlation coefficent-Spearman

\begin{tabular}{ll}
\hline Correlation coefficient & Correlation significance \\
\hline $0.80-1.0$ & Very strong \\
$0.60-0.79$ & Strong \\
$0.40-0.59$ & Moderate \\
$0.20-0.39$ & Weak \\
$0.00-0.19$ & Very weak \\
\hline
\end{tabular}

values can be modeled as linear. The Poisson probability density function is given by

$\operatorname{Pr}\left\{Y=y_{i}\right\}=\frac{e^{-\mu} \mu^{y_{i}}}{y_{i} !}$,

where $\mu$ is the Poisson parameter. When $\mu>0$, the mean and variance are equal to the expected number $\mathrm{E}(\mathrm{Y})$. Typically,
Table 4 Interpretation of correlation coefficient-Pearson and Kendall

\begin{tabular}{ll}
\hline Correlation coefficient & Correlation significance \\
\hline $0.90-1.0$ & Very high positive correlation \\
$0.70-0.90$ & High positive correlation \\
$0.50-0.70$ & Moderate positive correlation \\
$0.30-0.50$ & Low positive correlation \\
$0.00-0.30$ & Negligible correlation \\
\hline
\end{tabular}

the relationship between the explanatory variables and the Poisson parameter is a log-linear model,

$\mu=e^{\beta X_{i}}$,

where $X_{i}$ is a vector of explanatory variables and $\beta$ is a vector of estimable parameters.
Table 2 Spearman's correlation between intersection rear-end crash counts and number of hard-braking events by distance, for northbound SR-37

\begin{tabular}{|c|c|c|c|c|c|c|}
\hline \multirow[t]{2}{*}{ Int ID } & \multicolumn{3}{|l|}{$0-400 \mathrm{ft}$} & \multicolumn{3}{|c|}{$400-1320 \mathrm{ft}$} \\
\hline & $r_{s}$ & $p$ value & $\begin{array}{l}\text { Strong } \\
\text { correlation }\end{array}$ & $r_{s}$ & $p$ value & $\begin{array}{l}\text { Strong } \\
\text { correlation }\end{array}$ \\
\hline 1 & 0.23 & 0.11 & & 0.21 & 0.15 & \\
\hline 2 & 0.10 & 0.52 & & $0.44 *$ & 0.002 & \\
\hline 3 & 0.25 & 0.09 & & $0.33 * *$ & 0.02 & \\
\hline 4 & 0.16 & 0.28 & & 0.28 & 0.06 & \\
\hline 5 & -0.15 & 0.31 & & $0.33 * *$ & 0.02 & \\
\hline 6 & 0.20 & 0.18 & & 0.2 & 0.19 & \\
\hline 7 & $0.34 * *$ & 0.02 & & 0.15 & 0.32 & \\
\hline 8 & $0.42 *$ & $<0.001$ & & $0.65^{*}$ & $<0.001$ & $\checkmark$ \\
\hline
\end{tabular}

* Significant at $99 \%$ CL

${ }^{* *}$ Significant at $95 \% \mathrm{CL}$

\begin{tabular}{|c|c|c|c|c|c|c|}
\hline \multirow[t]{2}{*}{ Int ID } & \multicolumn{3}{|c|}{$0-400 \mathrm{ft}$} & \multicolumn{3}{|c|}{$400-1320 \mathrm{ft}$} \\
\hline & $r_{s}$ & $p$ value & $\begin{array}{l}\text { Strong } \\
\text { correlation }\end{array}$ & $r_{s}$ & $p$ value & $\begin{array}{l}\text { Strong } \\
\text { correlation }\end{array}$ \\
\hline 1 & $0.54 *$ & $<0.001$ & & 0.15 & 0.32 & \\
\hline 2 & 0.15 & 0.3 & & 0.08 & 0.58 & \\
\hline 3 & $0.55^{*}$ & $<0.001$ & & $0.57 *$ & $<0.001$ & \\
\hline 4 & $0.53 *$ & $<0.001$ & & $0.72 *$ & $<0.001$ & $\checkmark$ \\
\hline 5 & $0.44 *$ & 0.002 & & $0.61 *$ & $<0.001$ & $\checkmark$ \\
\hline 6 & $0.46^{*}$ & 0.001 & & $0.31 * *$ & 0.03 & \\
\hline 7 & 0.12 & 0.14 & & 0.22 & 0.13 & \\
\hline 8 & $0.33^{* *}$ & 0.022 & & 0.23 & 0.11 & \\
\hline
\end{tabular}

*Significant at $99 \% \mathrm{CL}$

** Significant at $95 \% \mathrm{CL}$ 
Table 5 Pearson's correlation between intersection rear-end crash counts and number of hard-braking events by distance, for southbound SR-37

\begin{tabular}{|c|c|c|c|c|c|c|}
\hline \multirow[t]{2}{*}{ Int ID } & \multicolumn{3}{|c|}{$0-400 \mathrm{ft}$} & \multicolumn{3}{|c|}{$400-1320 \mathrm{ft}$} \\
\hline & $r_{s}$ & $p$ value & $\begin{array}{l}\text { Moderate } \\
\text { correlation }\end{array}$ & $r_{s}$ & $p$ value & $\begin{array}{l}\text { Moderate } \\
\text { correlation }\end{array}$ \\
\hline 1 & 0.54 & $<0.001$ & $\checkmark$ & 0.06 & 0.68 & \\
\hline 2 & 0.07 & 0.63 & & 0.06 & 0.67 & \\
\hline 3 & 0.42 & 0.00 & & 0.40 & 0.00 & \\
\hline 4 & 0.51 & $<0.001$ & $\checkmark$ & 0.66 & $<0.001$ & $\checkmark$ \\
\hline 5 & 0.43 & 0.00 & & 0.62 & $<0.001$ & $\checkmark$ \\
\hline 6 & 0.44 & 0.00 & & 0.26 & 0.07 & \\
\hline 7 & 0.08 & 0.57 & & 0.12 & 0.41 & \\
\hline 8 & 0.34 & 0.02 & & 0.23 & 0.12 & \\
\hline
\end{tabular}

Table 6 Kendall's correlation between intersection rear-end crash counts and number of hard-braking events by distance, for southbound SR-37

\begin{tabular}{|c|c|c|c|c|c|c|}
\hline \multirow[t]{2}{*}{ Int ID } & \multicolumn{3}{|c|}{$0-400 \mathrm{ft}$} & \multicolumn{3}{|c|}{$400-1320 \mathrm{ft}$} \\
\hline & $r_{s}$ & $p$ value & $\begin{array}{l}\text { Moderate } \\
\text { correlation }\end{array}$ & $r_{s}$ & $p$ value & $\begin{array}{l}\text { Moderate } \\
\text { correlation }\end{array}$ \\
\hline 1 & 0.45 & $<0.001$ & & 0.14 & 0.32 & \\
\hline 2 & 0.14 & 0.28 & & 0.08 & 0.58 & \\
\hline 3 & 0.44 & $<0.001$ & & 0.48 & $<0.001$ & \\
\hline 4 & 0.40 & $<0.001$ & & 0.61 & $<0.001$ & $\checkmark$ \\
\hline 5 & 0.36 & 0.00 & & 0.53 & $<0.001$ & $\checkmark$ \\
\hline 6 & 0.39 & 0.00 & & 0.28 & 0.03 & \\
\hline 7 & 0.11 & 0.40 & & 0.21 & 0.13 & \\
\hline 8 & 0.28 & 0.02 & & 0.21 & 0.11 & \\
\hline
\end{tabular}

The data is considered over-dispersed, when the variance of the response variable is larger than its mean. This can typically be modeled using a negative binomial model, which can be derived from (2). For each observation $i$

$\mu_{i}=e^{\left(\beta X_{i}+\varepsilon_{i}\right)}$,

where $e^{\varepsilon_{\mathrm{i}}}$ is a Gamma-distributed disturbance term with a mean of 1 and a variance of $\alpha$ (Washington 2010). The added disturbance term allows the variance and the mean to differ as shown below

$\operatorname{VAR}\left[y_{i}\right]=E\left[y_{i}\right]\left[1+\alpha E\left[y_{i}\right]\right]+\alpha E\left[y_{i}\right]^{2}$.

The probability density function for the negative binomial model is defined as

$P\left(y_{i}\right)=\frac{\Gamma\left((1 / \alpha)+y_{i}\right)}{\Gamma(1 / \alpha)+y_{i} !}\left(\frac{(1 / \alpha)}{(1 / \alpha)+\mu_{i}}\right)^{(1 / \alpha)}\left(\frac{\mu_{i}}{(1 / \alpha)+\mu_{i}}\right)^{y_{i}}$.

The Poisson model is a special case of the negative binomial model for when $\alpha$, also known as the over-dispersion parameter, is considered to be equal to zero. The generalized linear model of the mean $\mu$ on the predictor vector $X_{\mathrm{i}}$ is formulated as

$L(\mu)=\beta_{i} X_{i}^{T}$

Table 7 shows the descriptive statistics for the model variables.

The Poisson and negative binomial models are considered. The variance of the response variable is larger than the mean of the response variable indicating the data may be over dispersed and favoring a negative binomial model. However, under the negative binomial model the overdispersion parameter is not significant. Therefore, the Poisson model is selected.

Table 8 presents the results of the data. Of the seven variables, only two, hard-braking and volume were found to be significant. The McFadden $\rho^{2}$ is an indicator of the overall fit of the model and is given by

$\rho^{2}=1-\frac{\operatorname{LL}(\beta)}{\operatorname{LL}(0)}$

where $\operatorname{LL}(\beta)$ is the log-likelihood at convergence with a parameter vector $\beta$ and $\operatorname{LL}(0)$ is the initial log-likelihood. 


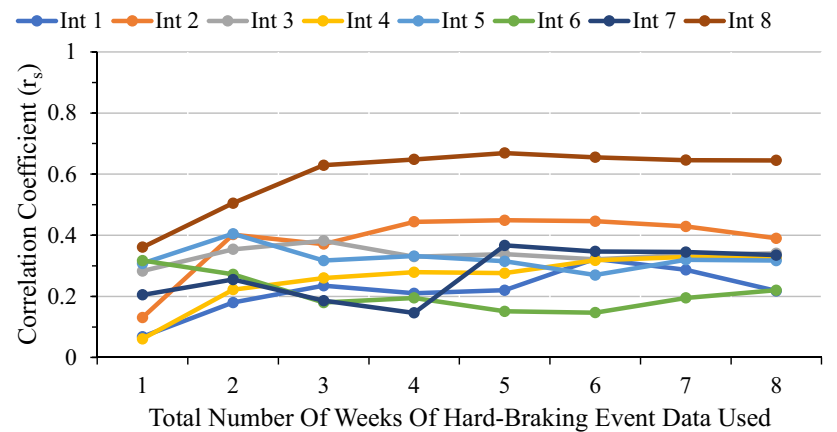

(a) $\mathrm{NB} 400-1320 \mathrm{ft}$

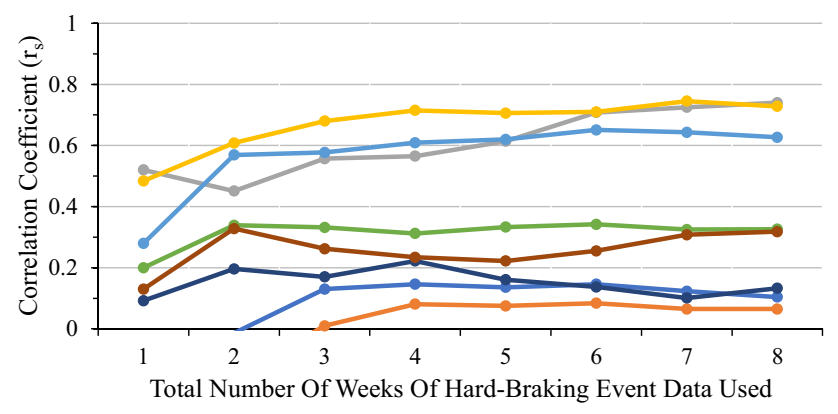

(b) $\mathrm{SB} 400-1320 \mathrm{ft}$

Fig. 10 Sensitivity analysis for Spearman correlation between hardbraking events and rear-end crashes for 8 weeks in July and August 2019

Varying between zero and 1 , a $\rho^{2}$ closer to one indicates a better model. The $\rho^{2}$ statistic for the given model is estimated to be 0.19 , pointing to the preliminary nature of this model and the limited nature of the hard-braking event dataset. The parameters show that the number of rear-end crashes increase significantly with an increase in hard-braking event counts, which is fairly intuitive. Additionally, it also follows naturally that an increase in volumes will lead to an increase in rear-end crash counts according to the model's parameters.

\section{Summary and Discussion}

This study compared crash data over a period of 4.5 years (January 2016 to July 2019) at eight signalized intersections with one month of hard-braking data (July 2019) to determine if there was a statistical relationship between crashes and hard-braking events. Geospatial analysis was conducted on more than 6 million records to associate nearly 7,000 hard-braking events occurring on this corridor. Graphical illustrations comparing aggregated hardbraking events and crashes (Figs. 4, 5 and 9) demonstrated a visual relationship between the two data sets. Statistical tests showed that three intersections ( $8 \mathrm{NB}, 4 \mathrm{SB}$, and $5 \mathrm{SB}$ ) had a strong correlation between rear-end crashes and hard-braking events occurring past $400 \mathrm{ft}$ from the stop bar (Tables 2 and 3). The same three intersections showed high hard-braking counts, farther away than 400 $\mathrm{ft}$ from the stop bar, in comparison with the rest of the corridor (Figs. 4b and 5b). This could indicate that the hard-braking and rear-end crashes correlation is stronger at locations where vehicles are hard-braking far away from the stop bar (perhaps due to long queues). Results from the sensitivity analysis showed that a sample size of at least 4 weeks of hard-braking events is needed to result in reliable correlation with crash data (Fig. 10). Finally, results from the statistical modelling illustrated that the number

Table 8 Estimation results

\begin{tabular}{lll}
\hline Variable name & Estimate & $p$ value \\
\hline Hard-braking* & 0.50 & $<0.0001$ \\
Volume* & 0.0012 & $<0.0001$ \\
Number of observations & 768 & \\
Restricted log-likelihood (contestant only) & -602.34 & \\
Log-likelihood at convergence & -490.64 & \\
Chi-squared & 223.40 & \\
McFadden $\rho^{2}$ & 0.19 & \\
\hline
\end{tabular}

* Significant at $99 \%$ confidence level
Table 7 Descriptive statistics for model variables

\begin{tabular}{|c|c|c|c|}
\hline Variable name & Description & Mean & Std. Dev \\
\hline Crash & crash count by 30 -min bins & 0.34 & 0.71 \\
\hline Hard-braking & Hard-braking event count totaled for July & 2.41 & 4.87 \\
\hline Volume & Volumes by 30 -min bins & 1042.58 & 631.80 \\
\hline Lanes & Number of lanes & 4.25 & 0.43 \\
\hline Barrels & Barrel median present ( $1=$ "yes", $0=$ "no") & 0.19 & 0.39 \\
\hline Cement & Cement median present ( $1=$ "yes", $0=$ "no") & 0.19 & 0.39 \\
\hline Right & Exclusive right present ( $1=$ "yes", $0=$ "no") & 0.88 & 0.33 \\
\hline Left & Exclusive left present ( $1=$ "yes", $0=$ "no") & 0.94 & 0.24 \\
\hline
\end{tabular}


crashes can significantly increase with increase in number of hard-braking events and volume (Table 8).

The correlation shown between rear-end crashes and hard-braking events is particularly beneficial to agencies because statistically valid data can be collected in a month or two, instead of waiting the traditional 3-5 years for a statistically significant number of crashes to occur. Histograms like the one shown in Figs. 6 and 7, can provide agencies with a high fidelity perspective on exactly where those events may be clustered to assess potential mitigation measures.

The techniques described in this paper are also scalable to larger numbers of intersections and corridors. Agencies could implement this method to assess all traffic signals within an urban area or an entire state. Such analysis would be a relatively modest effort, and perhaps more importantly, require no investment in traffic signal infrastructure to collect this performance measure data.

Acknowledgements Hard-braking event and trajectory data from July 1 to July 31, 2019, used in this study, was provided by Wejo Data Services, Inc. This work was supported in part by the Joint Transportation Research Program and Pooled Fund Study (TPF-5(377)) led by the Indiana Department of Transportation (INDOT) and supported by the state transportation agencies of California, Connecticut, Georgia, Minnesota, North Carolina, Ohio, Pennsylvania, Texas, Utah, Wisconsin, plus the City of College Station, Texas, and FHWA Operations Technical Services Team. The contents of this paper reflect the views of the authors, who are responsible for the facts and the accuracy of the data presented herein, and do not necessarily reflect the official views or policies of the sponsoring organizations. These contents do not constitute a standard, specification, or regulation.

Author Contributions The authors confirm contribution to the paper as follows:

Study conception and design: Margaret Hunter, Enrique SaldivarCarranza, Jairaj Desai, Jijo Mathew, Howell Li, and Darcy M. Bullock. Data collection: Margaret Hunter, Enrique Saldivar-Carranza, and Jairaj Desai. Analysis and interpretation of results: Margaret Hunter, Enrique Saldivar-Carranza, Jairaj Desai, Jijo Mathew, Howell Li, and Darcy M. Bullock. Draft manuscript preparation: Margaret Hunter, Enrique Saldivar-Carranza, Jairaj Desai, Jijo Mathew, Howell Li, and Darcy M. Bullock.

Funding The authors disclose receipt of the following financial support for the research, authorship, and/or publication of this article: This work was supported by the Joint Transportation Research Program and the Pooled Fund Study (TPF-5(377)) led by the Indiana Department of Transportation (INDOT).

Availability of Data and Material The data that support the findings of this study are available from the corresponding author, Jijo K. Mathew, upon reasonable request.

\section{Declarations}

Conflict of interest/competing interests The authors declare no potential conflicts of interest with respect to the research, authorship, and/or publication of this article.
Open Access This article is licensed under a Creative Commons Attribution 4.0 International License, which permits use, sharing, adaptation, distribution and reproduction in any medium or format, as long as you give appropriate credit to the original author(s) and the source, provide a link to the Creative Commons licence, and indicate if changes were made. The images or other third party material in this article are included in the article's Creative Commons licence, unless indicated otherwise in a credit line to the material. If material is not included in the article's Creative Commons licence and your intended use is not permitted by statutory regulation or exceeds the permitted use, you will need to obtain permission directly from the copyright holder. To view a copy of this licence, visit http://creativecommons.org/licenses/by/4.0/.

\section{References}

Bagdadi O (2013) Assessing safety critical braking events in naturalistic driving studies. Transport Res F 16:117-126. https://doi.org/ 10.1016/j.trf.2012.08.006

Bagdadi O, Várhelyi A (2013) Development of a method for detecting jerks in safety critical events. Accid Anal Prev 50:83-91. https:// doi.org/10.1016/j.aap.2012.03.032

Chan YH (2003) Biostatistics 104: Correlation Analysis. Singap Med J 44(12):614-619

Dancey CP, Reidy J (2007) Statistics without Maths for Psychology. Person Education, London

Chen P, Guizhen Yu, Xinkai Wu, Ren Y, Li Y (2017) Estimation of red-light running frequency using high-resolution traffic and signal data. Accid Anal Prev 102:235-247. https://doi.org/10.1016/j. aap.2017.03

Day CM, Brennan TM, Premachandra H, Sturdevant JR, Bullock DM (2011) Analysis of peer data on intersections for decisions about coordination of arterial traffic signal. Transp Res Rec 2259(1):2336. https://doi.org/10.1007/s42421-020-00024-x

Day CM, Bullock DM (2016) Detector-free signal offset optimization with limited connected vehicle market penetration: Proof-ofConcept Study. Transp Res Rec 2558(1):54-65. https://doi.org/ 10.3141/2620-06

Day CM., Darcy MB , Li H, Remias SM, Hainen AM, Freije RS, Stevens AL, Sturdevant JR, Brennan TM Jr (2014) Performance Measures for Traffic Signal Systems: An Outcome-Oriented Approach. https://doi.org/https://doi.org/10.5703/1288284315333

Day CM, Li H, Richardson LM, Howard J, Platte T, Sturdevant JR, Bullock DM (2017) Detector-free optimization of traffic signal offsets with connected vehicle data. Transp Res Rec 2620(1):54 68. https://doi.org/10.3141/2620-06

Desai J, Li H, Mathew JK, Cheng Y-T, Habib A, Bullock DM (2020) Correlating hard-braking activity with crash occurrences on interstate construction projects in Indiana. J Big Data Anal Transp. https://doi.org/10.1007/s42421-020-00024-X

Essa M, Sayed T (2019) Full Bayesian conflict-based models for real time safety evaluation of signalized intersections. Accid Anal Prev 129:367-381. https://doi.org/10.1016/j.aap.2018.09.017

Evans JD (1996) Straightforward statistics for the behavioral sciences. Thomson Brooks, Pacific Grove

Federal Highway Administration. (2011) Road Safety Information Analysis: A Manual for Local Rural Road Owners. Available via DIALOG. https://safety.fhwa.dot.gov/local_rural/training/fhwas a1210/lrro_data.pdf

Gazis D, Herman R, Maradudin A (1960) The problem of the amber signal light in traffic flow. Oper Res 8(1):112-132. https://doi.org/ 10.1287/opre.8.1.112

Hainen AM, Stevens AL, Freije RS, Day CM, Sturdevant JR, Bullock DM (2014) High-resolution event-based data at diamond 
interchanges. Transpo Res Rec 2439(1):12-26. https://doi.org/ 10.3141/2439-02

Indiana Department of Transportation (2012) Chapter 5: Engineering Assessment. In: Indiana Design Manual. Available via DIALOG. https://www.in.gov/indot/design_manual/files/Ch05_2013.pdf

Kendall, Maurice G and Jean Dickinson Gibbons (1990). Rank Correlation Methods. New York, NY

Kveladze I, Agerholm N (2020) GeoVisual analytics for understanding the distribution of speeding patterns on arterial roads: assessing the traffic safety of vulnerable road users. J Locat Based Serv 14(3):201-230. https://doi.org/10.1080/17489725.2020.1823497

Lavrenz SM, Day CM, Grossman J, Freije R, Bullock DM (2016) Use of high-resolution signal controller data to identify red light running. Transp Res Rec 2558(1):41-53. https://doi.org/10.3141/ 2558-05

Li H, Mathew J, Kim W, Bullock D (2020) Using crowdsourced vehicle braking data to identify roadway hazards. JTRP Affil Rep. https:// doi.org/10.5703/1288284317272

Mekker MM, Remias SM, Mcnamara ML, Bullock DM (2014) Characterizing interstate crash rates based on traffic congestion using probe vehicle data. JTRP Affil Rep 16:2014-2015. https://doi.org/ $10.5703 / 1288284317119$

Mukka MM (2012) A guide to appropriate use of correlation coefficient in medical research. Malawi Med J 24(3):69-71

Older SJ, Spicer BR (1976) Traffic conflicts-a development in accident research. Hum Factors 18(4):335-350. https://doi.org/10. 1177/001872087601800403

Parsonson PS (1978) Signalization of high speed isolated intersections. Transp Res Rec 681:34-42

Pearson K (1895) Note on regression and inheritance in the case of two parents. Proc R Soc Lond 58:240-242

Perkins SR, Harris JI (1968) Traffic conflict characteristics-accident potential at intersections. Highw Res Rec 225:35-43

Remias SM, Hainen AM, Day CM, Brennan TM, Li H, Rivera-Hernandez E, Sturdevant JR, Young SE, Bullock DM (2013) Performance characterization of arterial traffic flow with probe vehicle data. Transp Res Rec 2380(1):10-21. https://doi.org/10.3141/2380-02

Sharma A, Bullock D, Peeta S (2011) Estimating dilemma zone hazard function at high speed isolated intersection. Transp Res Part C 19(3):400-412. https://doi.org/10.1016/j.trc.2010.05.002
Spearman C (1904) The proof and measurement of association between two things. Am J Psychol 15(1):72

Stipancic J, Miranda-Moreno L, Saunier N (2018) Vehicle Manoeuvers as Surrogate Safety Measures: extracting data from the Gps-enabled smartphones of regular drivers. Accid Anal Prev 115:160169. https://doi.org/10.1016/j.aap.2018.03.005

Sturdevant J, Overman T, Raamot E, Deer R, Miller D, Bullock D, Day C, Brennan T, Li H, Hainen A, Remias S (2012) Indiana traffic signal Hi resolution data logger enumerations. JTRP Data Papers. https://doi.org/10.5703/1288284316998

Tarko, Andrew P. (2020) Traffic Conflicts as Crash Surrogates. In: Measuring Road Safety Using Surrogate Events, Elsevier Ltd, pp 31-45

Washington, Simon P, Matthew G. Karlaftis, and Fred L Mannering (2010) Statistical and Econometric Methods for Transportation Data Analysis. Boca Raton, FL

Wejo and CtrlShift (2020) The Connected Car Data Market. In: The Growth of the Connected Vehicle Data Market - The Implications of Personal Data and Emerging US Legislation. Available via DIALOG. https://www.wejo.com/news

Wu X, Liu HX, Gettman D (2010) Identification of oversaturated intersections using high-resolution traffic signal data. Transp Res Part C 18(4):626-638. https://doi.org/10.1016/j.trc.2010.01.003

Zegeer CV, Deen RC (1978) Green-extension systems at high-speed intersections. ITE J 48(11):4-5. https://doi.org/10.13023/KTC. RR.1978.496

Zheng J, Liu HX, Misgen S, Schwartz K, Green B, Anderson M (2014) Use of event-based traffic data in generating time-space diagrams for evaluation of signal coordination. Transp Res Rec 2439(1):94104. https://doi.org/10.3141/2439-09

Publisher's Note Springer Nature remains neutral with regard to jurisdictional claims in published maps and institutional affiliations. 